\title{
ANÁLISE DE COINTEGRAÇÃO E GERAÇÃO DE CENÁRIOS NA ALOCAÇÃO DE INVESTIMENTOS EM PREVIDÊNCIA COMPLEMENTAR
}

\section{1- Wevergton Junior Adão*}

Mestre pelo Programa de Pós-Graduação Stricto Sensu da Pontifícia Universidade Católica do Paraná (PUC-PR), Brasil. wjadao@spaipa.com.br

http://lattes.cnpq.br/5434357943496024

\section{2- Wesley Vieira Silva}

Doutorado em Engenharia de Produção pela Universidade Federal de Santa Catarina (UFSC), Brasil.

Professor e Coordenador do Programa de Pós-Graduação Stricto Sensu em Administração da Pontifícia Universidade

Católica do Paraná (PUC-PR), Brasil.

wesley.vieira@pucpr.br

http://lattes.cnpq.br/1710286275396858

\section{3- June Allison W. Cruz}

Doutorado em Administração pela Pontifícia Universidade Católica do Paraná (PUC/PR), Brasil.

Professor do Programa de Pós-Graduação Stricto Sensu em Administração da Pontifícia Universidade Católica do Paraná (PUC/PR), Brasil.

june.cruz@pucpr.br

http://lattes.cnpq.br/7748990070387779

\section{4- Jansen Maia Del Corso}

Doutorado em Administração da Produção pela Escuela Superior de Administración y Dirección de Empresas(ESADE), Espanha.

Professor do Programa de Pós-Graduação Stricto Sensu em Administração da Pontifícia Universidade Católica do Paraná (PUC/PR), Brasil.

del.corso@pucpr.br

http://lattes.cnpq.br/7710268791711645

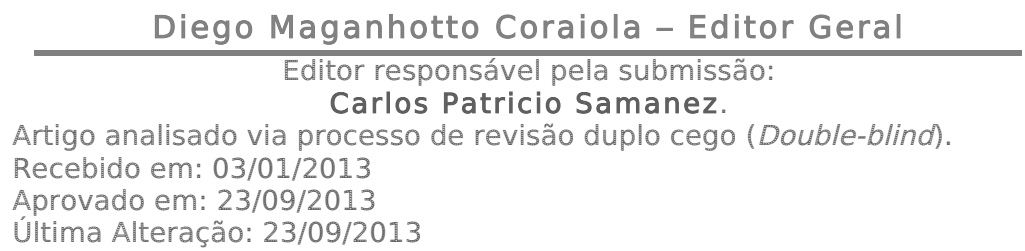

* Contato Principal: Rua Imaculada Conceição, 1155, Bloco Acadêmico, Mestrado/Doutorado em Administração, Bairro Prado Velho, Curitiba - PR. CEP: 80.215-901. 


\section{ANÁLISE DE COINTEGRAÇÃo E GERAÇÃo dE CENÁRIOS NA ALOCAÇÃo DE INVESTIMENTOS EM PREVIDÊNCIA COMPLEMENTAR}

\section{RESUMO}

O objetivo desse trabalho é apresentar uma aplicação por meio da modelagem de alocação de carteiras de investimentos analisando as relações de longo prazo entre os ativos financeiros e indicadores econômicos, por meio da técnica de cointegração. Os dados observados são séries temporais de indicadores econômicos e do mercado financeiro, compreendendo o período de implantação do plano Real. Os resultados obtidos auxiliam na compreensão da estrutura de decisão de uma Entidade Fechada de previdência complementar, gerando informações sobre as relações de longo prazo das variáveis que servem como subsídio para a geração de cenários probabilísticos. As diversas táticas de investimentos são avaliadas quanto ao seu desempenho ao longo de 40 anos de projeção. A validação dos resultados é realizada pautando-se no pacote estatístico S-Plus, permitindo um aprofundamento sobre a estratégia a ser adotada, levando-se em consideração a necessidade de gestão dos riscos, em específico aqueles associados à manutenção da solvência do plano de previdência.

Palavras-chave

Asset Liability Management (ALM); Fundos de Pensão; Cointegração.

\section{GENERATION OF SCENARIOS AND COINTEGRATION ANALYSIS FOR ALLOCATION INVESTMENT IN SUPPLEMENTARY PENSION FUND}

\section{ABSTRACT}

The objective of this work is to present for an investment portfolio allocation taking into consideration long-term relations between financial assets and economy indexes. The observed data are from a time series of economic indicators, as well the financial market, encompassing the period of the Real Plan establishment. The gathered results assist in the understanding of decision structures from a Closed Pension Fund, generating information on the relations of long-term period from variables which can be used as parameters for probabilistic scenarios. All things considered, several tactics of investments are evaluated in terms of their performance throughout a 40year projection. The validation of results is carried through by means of a statistical package S-Plus, allowing a deeper analysis over the strategy adopted, regarding the need of risks management, specifically those associated with the maintenance of the pension fund solvency.

\section{Keywords}

Asset Liability Management (ALM); Pension Fund; Cointegration. 


\section{Introdução}

A previdência complementar existe no Brasil desde o início do século 20, no entanto, seu desenvolvimento ocorreu somente nos últimos 30 anos, quando passou a assumir a responsabilidade fomentar o mercado de capitais brasileiro, recebendo os contornos atuais somente a partir da Constituição de 1988. Outro fator, de particular relevância, foi o desenvolvimento da previdência complementar, motivada pela incapacidade do regime geral de garantir a segurança do trabalhador no futuro. Assim, a previdência complementar se estabeleceu como um participante importante no mercado de capitais, dado que o volume de recursos aplicados em previdência complementar equivale a aproximadamente $17 \%$ do PIB brasileiro em 2006.

Nesse sentido, as Entidades Fechadas de Previdência Complementar, ou simplesmente EFPC's, são pessoas jurídicas criadas com o objetivo de administrar e executar planos de natureza previdenciária. Sua função é garantir o pagamento de benefícios de aposentadoria e pensão, por meio do recebimento de contribuições ao longo da vida laborativa dos participantes, que se tornarão ativos de investimento. Este processo de acumulação de poupança ou reserva financeira se estende ao longo de todo o tempo em que o participante estiver vinculado de alguma forma ao plano.

A previdência complementar faculta aos trabalhadores, de uma forma conjunta e organizada, estabelecer uma proteção mútua que garanta o direito ao recebimento de complementação de renda na aposentadoria, além de amparar a família do trabalhador no caso de invalidez e morte, por exemplo.

Basicamente o perfil dos investimentos é conservador, orientado pela formação de poupança em longo prazo, com objetivo de converter estes recursos em um benefício de aposentadoria. A gestão dos investimentos não é o objetivo final da EFPC, mas o meio para chegar ao objetivo principal de garantir o pagamento de benefícios futuros a partir da formação de uma poupança previdenciária. Esta poupança, também chamada de reserva, é formada pela adequada remuneração das contribuições dos participantes ao longo do tempo, utilizando-se para isso os instrumentos do mercado financeiro à disposição.

A alocação de investimentos é tema importante dentro da estratégia dos fundos de pensão, relacionado diretamente com o objetivo dos fundos de pensão. Ao contrário de outros players do mercado financeiro, as EFPC's buscam ter, em suas carteiras de investimentos, predominância de ativos financeiros com prazos de maturidade mais longos. A responsabilidade de honrar o pagamento dos benefícios de aposentadoria e pensão durante vários anos e até décadas revela um desafio que exige cuidados na elaboração de sua estratégia.

Este trabalho encontra-se estruturado em cinco seções que podem ser resumidas da seguinte forma: a primeira trata da parte introdutória; a segunda diz respeito ao referencial teórico-empírico; a terceira trata da metodologia da pesquisa; a quarta diz respeito a apresentação e análise dos resultados e a quinta refere-se as considerações finais, limitações e recomendações para trabalhos futuros.

\section{Referencial Teórico-Empírico}

\subsection{Análise de Cointegração}

A abordagem sobre a métrica de análise de cointegração ganhou destaque ao longo dos últimos anos, principalmente na aplicação em modelos econométricos, por ser uma ferramenta sólida de modelagem dinâmica de dados, ao longo de séries de tempo. A aplicação da métrica também se estendeu para a análise na gestão de investimentos, mais especificamente para as EFPC's, em função da necessidade de estabelecer suas estratégias de investimentos a longo prazo.

O trabalho apresentado por Sargan (1964) sobre o modelo de correção de erros pode ser considerado a primeira abordagem, porém, somente a partir de 1986, na publicação de agosto da Oxford Bulletin of Economics and Statistics, o termo cointegração passou a ser empregado na literatura (Margarido, Oliveira e Souza, 2006).

Neste ano, Granger publicou o artigo intitulado Developments in the Study of Cointegrated Variables, e em 1987 Engle e Granger publicaram o trabalho Cointegration and Error Correction: Representation, Estimation and Testing. A partir daí, diversos outros autores como Johansen (1988), Hamilton (1994), Enders (1995), Harris (1995) e Hendry (1995) desenvolveram estudos sobre o assunto.

A cointegração não se baseia somente na análise dos retornos, mas em toda a estrutura de relação entre preços, taxas e rentabilidades no longo prazo, onde os dados ao longo do tempo estão ligados por uma tendência estocástica.

O processo de cointegração é feito em duas etapas: 1ạ) a identificação das relações de equilíbrio de longo prazo entre os preços, e; $2^{\mathrm{a}}$ ) uma estimativa de um modelo dinâmico de correlação dos retornos. Ou seja, os dados usualmente apresentam tendências de longo prazo, mas, nos períodos curtos ocorrem movimentos aparentemente de desequilíbrio, que na verdade podem ser uma tendência estocástica agindo de forma a ajustar uma tendência de longo prazo.

Destaca-se que tanto a cointegração quanto a correlação, embora relacionadas, possuem conceitos diferentes. Assi, uma elevada correlação não implica necessariamente elevada cointegração e vice-versa. As séries temporais cointegradas podem possuir níveis de correlações que, às vezes, são muito baixas. Almeida (1997) traz um exemplo acerca dessa diferenciação: um grande e diversificado portfólio de ações de um índice 
de ações, em que as alocações são determinadas pelos seus pesos no índice, deve ser cointegrado com o índice. Ainda que o portfólio deva se mover em linha com o índice de ações no longo prazo, pode haver períodos em que as ações, que não estão no portfólio, tenham movimentos excepcionais de preços. Logo, as correlações empíricas entre o portfólio e o índice podem ser, antes de tudo, baixas durante certo tempo. O inverso também pode ocorrer, isto é, os retornos podem ser altamente correlacionados sem que haja elevada cointegração nos preços. É importante acrescentar que as altas correlações podem facilmente ocorrer quando há e quando não há cointegração. Portanto, a correlação nada nos diz a respeito da relação comportamental de longo prazo entre dois mercados: eles podem ou não estar se movendo juntos ao longo de grandes períodos, e a correlação não é a ferramenta adequada para medir isso. A correlação reflete os movimentos conjuntos dos retornos, responsáveis pelas grandes instabilidades ao longo do tempo. Nesse contexto, o uso da cointegração é justificado em função de se tratar de séries temporais usados por gestores de investimentos institucionais que visam gerir os recursos em longo prazo, o que certamente vai ao encontro da metodologia aqui adotada.

Em tempo, é importante ressaltar que dados do mercado financeiro geralmente apresentam comportamentos diferentes quando tratados na forma de retorno e preço, merecendo tratamentos diferenciados. Os retornos dos preços geralmente apresentam comportamento de reversão à média, e são conhecidos como processos estacionários. É neste caso que se aplicam os métodos mais comuns de análise de risco baseado no risco-retorno.

A construção do modelo VAR tem o objetivo de realizar projeções para as variáveis envolvidas, segundo Lutkepohl (2005, p. 151). O autor ainda destaca os procedimentos disponíveis para a escolha do número de defasagens adequado para realizar as projeções das variáveis, chamado de modelo de critério de seleção. O critério consiste em estimar modelos $\operatorname{VAR}(p)$ com ordem $p=0,1,2, \ldots, p_{\text {máx }}$ e escolher o valor de " $p$ " que minimize algum modelo de critério de seleção. Os três critérios de seleção mais comuns são o Akaike (AlC), Schwarz-Beysian (BIC) e o Hannan-Quinn (HQC).

\subsection{O Processo de Simulação na Formulação da Estratégia de Alocação}

Apesar da simulação de monte carlo ter se desenvolvido inicialmente na área industrial, sua aplicação se estendeu praticamente a todas as áreas do conhecimento. Segundo Shimizu (1975), os primeiros tipos de problemas tratados com o uso da simulação foram relacionados com o escoamento de veículos, pessoas ou materiais. Porém ao longo das últimas décadas a aplicação da simulação se estendeu para outras áreas, em especial à área de Finanças.

Assim, como em organizações de outros segmentos, a simulação é uma poderosa ferramenta como uma forma de explorar a realidade na formulação da estratégia em uma EFPC. Neste caso, um exemplo de aplicação direta consiste na avaliação da viabilidade do plano de previdência diante de possíveis decisões sobre a formação da poupança previdenciária.

Mintzberg (2000) reconhece a contribuição da simulação na estratégia em função da descrição dos fenômenos abordados, fornecendo subsídios para o planejamento, previsão e análise. A simulação a partir de computadores é o modelo mais formal, que permite quantificar relações entre variáveis e reproduzir aspectos da realidade das organizações com realismo.

O uso da simulação, segundo a visão do autor supracitado, permite sistematizar uma série de aspectos que até então compunham apenas o subconsciente dos gerentes, criando uma dependência excessiva da capacidade individual sobre a formulação de estratégias.

O uso da simulação não busca desconsiderar a capacidade individual das pessoas no processo de tomada de decisão, mas permitir que outros indivíduos, que não façam parte dos níveis gerenciais mais altos, também contribuam para a análise de maneira sistemática. Esta visão é bastante razoável uma vez que a posição ocupada pela alta direção, em alguns casos, não permite explorar um determinado aspecto, fenômeno ou evento dentro do todo que corresponde à estratégia da organização.

A simulação pode também contribuir para a validação das escolhas estratégicas, área do conhecimento que ainda oferece inúmeras oportunidades para ser explorada, de acordo com Brady (2000). Entre as aplicações possíveis dos modelos de simulação, o autor destaca o processo de formação da estratégia nas organizações, por meio da construção de cenários que permitem avaliar as escolhas estratégicas a partir da análise ex ante do ambiente, segundo Georganzas e Acar (1995).

A segunda aplicação apontada por Brady é o ensino da estratégia por meio de simulação como algo factível de avaliar a aderência da estratégia aos modelos teóricos. Jennings (2002) também aborda as contribuições para o processo de aprendizado da estratégia por meio dos modelos de simulação, em que é possível representar situações muito próximas da realidade e abordar aspectos relacionados à formulação do planejamento estratégico e das suas diversas etapas de implantação.

O insucesso das novas organizações é apontado, muitas vezes, como o resultado da ausência de ferramentas de gestão que frequentemente levam os gestores a falharem por não dominarem completamente as atividades ou recursos disponíveis, segundo Schwartz e Teach (2000). A solução apontada é dispor de um conjunto de ferramentas de gestão que contribuam para a criação de estratégias que permitam direcionar os 
recursos conforme apareçam as oportunidades, buscando a partir da modelagem, associar as estratégias escolhidas e o desempenho.

A literatura sugere que o sucesso da estratégia está no equilíbrio entre as visões analítica e a intuitiva, cada qual ocupando seu papel de relativa importância na análise do futuro. Mintzberg (2000) aborda o problema do "dilema do planejamento", tendo de um lado os planejadores, como aqueles que buscam basicamente os elementos analíticos, e de outro lado os gerentes, que em função do seu contato maior com a realidade, acabam por desenvolver traços mais intuitivos. Essas duas posições, aparentemente contrárias, apresentam uma situação na qual o planejador necessita de elementos que possam ser convertidos de maneira objetiva, e assim ser comunicadas à organização de uma maneira clara.

Por outro lado, os conhecimentos e experiências desenvolvidas pelos gerentes não podem ser ignorados, sob a pena de a estratégia fracassar em função do descolamento dos modelos com a realidade. O ideal é que os planejadores tenham acesso ao conhecimento desenvolvido pelos gerentes, de maneira que possam extrair os dados factuais, e assim finalmente desenvolver uma perspectiva de visão integrada.

Mesmo sem tratar especificamente a questão da modelagem por meio do sistema de computadores, Quinn (1978) aborda a estratégia a partir de uma análise dinâmica, construída a partir de subsistemas, como um processo evolutivo e incremental. Ou seja, cada aspecto da organização ou evento é analisado de maneira fragmentada e aprofundada.

Assim, é possível uma compreensão melhor sobre um assunto específico, e suas relações, além de permitir também uma homogeneização do conhecimento entre os planejadores e gerentes. Em Mintzberg (2000) a tarefa de identificar os dados factuais relevantes aos subsistemas é naturalmente atribuída à equipe de apoio, assim como sua sistematização.

\subsection{Análise do Ambiente e Construção de Cenários}

A análise do ambiente é fator determinante para a elaboração de estratégias de sucesso na gestão de investimentos. Os cenários são construídos como conjuntos de fatores ou condições possíveis, combinados em trajetórias ao longo do tempo.

Em Almeida (1997) são abordadas as análises ambientais como uma atividade não só para o planejamento estratégico, mas também para outras dimensões menores que podem contribuir para o sucesso da empresa ou do produto. Neste são identificadas as variáveis significativas e estabelecida uma estrutura lógica na análise, atribuindo critérios diferenciados para cada segmento do ambiente.

É preciso considerar que a geração de cenários não apresenta uma métrica única, podendo, inclusive, ser desenvolvida como combinação a partir de outros modelos básicos. Segundo Utterback (1979, pp. 136-138) os métodos para previsão de mudanças ambientais são: i) Quantificação da opinião de experts; ii) Extrapolação de tendências passadas; iii) Análise ou monitoramento do ambiente e, iv) Simulação de interação entre as mudanças e restrições das variáveis ambientais.

Em Fleisher e Bensoussan (2002, p. 287) os métodos de análise de cenários podem ser classificados em quantitativos ou qualitativos. Os autores apontam para o primeiro método os modelos econométricos gerados a partir de programas de computador que permitem modelar as relações e tendências a partir de relações estatísticas e matemáticas. Já os métodos qualitativos apresentados são os métodos intuitivos, método Delphi e análise de impacto cruzado. Os autores destacam ainda que a utilização de múltiplos cenários é uma forma que busca compensar os efeitos de erros freqüentes ao se tentar prever os contornos do futuro, ou seja o dimensionamento inadequado das mudanças (superestimar ou subestimar os eventos).

Por outro lado, a estrutura estratégica não pode ser tratada exclusivamente por elementos quantificáveis, desconsiderando os aspectos subjetivos da realidade como é abordado em Enriquez (1997). O autor compara a delimitação dos contornos do planejamento estratégico com a estrutura tecnocrática, cuja racionalidade limitada (Simon, 1997) é determinante sobre o comportamento da organização, quando existe uma pseudoparticipação dos indivíduos sobre a definição dos contornos da estrutura estratégica, ficando o poder em um nível superior a cargo dos experts.

Uma vez que estes experts dominam os conhecimentos quantitativos necessários para encontrarem as melhores soluções para a maioria dos problemas, e até antecipar as soluções com a utilização de modelos de previsão e simulação, então tudo o que foge da condição de ser quantificável acaba por ser descartada ou considerada irrelevante. Porém, em função da própria dinâmica, difícil de ser idealizada ou quantificada, o autor denomina a realidade da empresa e seu ambiente como "hipercomplexa", que aparentemente não é coerente com o princípio da racionalidade ilimitada. A solução apontada para contornar essa inconsistência é o planejamento levar em consideração a diversidade do mundo, mesmo sabendo previamente que não é possível abranger toda a sua complexidade, interagindo com os modelos de maneira a se adaptarem conforme as circunstâncias. 


\section{Metodologia da Pesquisa}

\subsection{Caracterização da Pesquisa}

Este trabalho pode ser caracterizado como uma pesquisa de natureza aplicada, tendo como objetivo de empregar conhecimentos básicos, neste caso a cointegração e, assim, gerar um processo de alocação de investimentos a partir de cenários estocásticos. Esta proposta está em linha com o conceito de pesquisa aplicada apresentada em Jung (2004) uma vez que, além de aplicar conhecimentos básicos e produzir um novo processo, pode gerar novos conhecimentos resultantes do processo de pesquisa.

Quanto ao objetivo da pesquisa o trabalho pode ser classificado como uma pesquisa descritiva, uma vez que o objetivo do estudo visa “a identificação, registro e análise das características, fatores ou variáveis que se relacionam com o fenômeno ou processo", segundo Jung (2004, p. 152). Cabe destacar que a proposta da pesquisa é analisar a estrutura que envolve o processo de decisão dos investimentos em uma EFPC, levando em conta a geração de cenários a partir das relações de longo prazo de variáveis econômicas e financeiras.

Quantos aos procedimentos de execução, a proposta de trabalho pode ser caracterizada como uma pesquisa operacional, tendo em vista a finalidade de orientar a melhor opção para a tomada de decisões. Segundo Jung (2004, p. 155) “A pesquisa operacional (P.O.) trata por meio do uso de ferramentas estatísticas e métodos matemáticos da otimização para a seleção do meio mais adequado para se obter o melhor resultado".

Após a coleta dos dados é elaborada a análise das relações a longo prazo entre as variáveis dos mercados econômico e financeiro, empregando modelos de simulação na validação das alocações possíveis em diversos cenários, estabelecendo uma análise, a posteriori, sobre a utilização dos cenários probabilísticos como elemento na definição da estratégia da EFPC.

Quanto ao tempo de aplicação o presente trabalho pode ser classificado como um estudo longitudinal, segundo Jung (2004, p. 165) define como aquele que "requer uma coleta de dados ao longo do tempo". Nesta pesquisa, o processo analisado inicia-se no mês de janeiro de 2008, em face da revisão periódica na Política de Investimentos, e se estende por aproximadamente 40 anos de projeção.

Em relação aos procedimentos técnicos a serem utilizados neste trabalho, pode ser classificado como uma pesquisa com delineamento Ex-post facto, em função das observações ocorrerem após seu acontecimento, impedindo qualquer tipo de interferência por parte do pesquisador.

\subsection{Coleta de Dados}

Diversas variáveis econômicas e financeiras poderiam ser analisadas para estabelecer as relações de longo prazo e, posteriormente, serem empregadas na geração de cenários probabilísticos.

Para as projeções e simulações são utilizadas séries temporais com dados em base mensal de índices de inflação, juros e índices de Bolsa de Valores. Os dados são coletados por meio da internet nos sites dos órgãos oficiais brasileiros, como Banco Central do Brasil, BOVESPA e o Instituto Brasileiro de Geografia e Estatística (IBGE).

Uma vez que os dados analisados são apresentados como séries de preços ao longo do tempo, é necessário transformá-los na forma de retornos, que são variáveis aleatórias e podem seguir uma distribuição de probabilidade teórica. Em alguns casos, os retornos podem seguir uma distribuição diferente da normal com caudas mais pesadas que uma distribuição normal teórica.

Os dados consistem em 162 observações, compreendendo o período de julho de 1994 a dezembro de 2007, o que corresponde ao período do Real como moeda. Anteriormente a este período o nível de inflação apurada era extremamente elevado, chegando a acumular uma variação no índice INPC em 12 meses, entre julho de 1993 e julho de 1994, de $4.105 \%$, conforme revela a Tabela 1, que apresenta a evolução histórica dos índices anualizados.

Tabela 1 - Variação Anual Acumulada

\begin{tabular}{cccccc}
\hline Ano & INPC & IGP-M & IPCA & Bovespa & SELIC \\
\hline 1994 & $742,01 \%$ & $952,26 \%$ & $733,17 \%$ & $830,02 \%$ & $1273,11 \%$ \\
1995 & $21,78 \%$ & $15,15 \%$ & $22,20 \%$ & $-1,26 \%$ & $54,72 \%$ \\
1996 & $9,08 \%$ & $9,16 \%$ & $9,53 \%$ & $62,15 \%$ & $26,92 \%$ \\
1997 & $4,33 \%$ & $7,72 \%$ & $5,21 \%$ & $44,02 \%$ & $26,39 \%$ \\
1998 & $2,48 \%$ & $1,78 \%$ & $1,65 \%$ & $-33,93 \%$ & $28,58 \%$ \\
1999 & $8,40 \%$ & $19,93 \%$ & $8,91 \%$ & $143,55 \%$ & $25,47 \%$ \\
2000 & $5,26 \%$ & $9,91 \%$ & $5,96 \%$ & $-10,77 \%$ & $17,40 \%$ \\
2001 & $9,40 \%$ & $10,34 \%$ & $7,65 \%$ & $-11,07 \%$ & $17,63 \%$ \\
2002 & $14,65 \%$ & $25,04 \%$ & $12,47 \%$ & $-17,13 \%$ & $19,34 \%$ \\
2003 & $10,34 \%$ & $8,68 \%$ & $9,26 \%$ & $93,71 \%$ & $22,84 \%$ \\
2004 & $6,12 \%$ & $12,35 \%$ & $7,58 \%$ & $17,68 \%$ & $16,31 \%$ \\
2005 & $5,04 \%$ & $1,21 \%$ & $5,68 \%$ & $27,40 \%$ & $19,15 \%$ \\
2006 & $2,81 \%$ & $3,83 \%$ & $3,14 \%$ & $32,49 \%$ & $15,05 \%$ \\
2007 & $5,16 \%$ & $7,75 \%$ & $4,46 \%$ & $43,65 \%$ & $11,88 \%$ \\
\hline
\end{tabular}

Fonte: IBGE (2007) FGV (2007) e Banco Central do Brasil (2007). 
Neste trabalho foi verificado se as séries são estacionárias, por meio de teste de hipótese de raiz unitária, baseado na estatística Dickey-Fuller Aumentado (ADF). A constatação de estacionaridade no comportamento das séries de tempo é uma das condições para realizar os testes de cointegração, que são apresentados posteriormente.

A Tabela 2 apresenta o resumo do teste ADF para as séries de tempo, e a estatística do teste de hipóteses sobre a parte determinística, constante e (ou) tendência, da melhor representação da estrutura de defasagem. Ou seja, para cada série de tempo considerada verifica-se a significância da modelagem da estrutura de defasagem maior que a primeira diferença, partindo da estatística de autocorrelação.

Tabela 2 - Resumo do Teste de Raiz Unitária ADF

\begin{tabular}{lccccc}
\hline \multirow{2}{*}{ Série } & Defasagens & \multicolumn{2}{c}{ Teste de Hipótese } & \multicolumn{2}{c}{ Resultado } \\
\cline { 3 - 6 } & & Constante & Tendência & Estatística & P-valor \\
\hline INPC & 6 & Sim & Não & 0,1438 & 0,9681 \\
IPCA & 6 & Sim & Não & 0,0328 & 0,9593 \\
IGP-M & 6 & Sim & Não & 0,6223 & 0,9900 \\
SELIC & 12 & Sim & Sim & $-0,6208$ & 0,9761 \\
\hline Bovespa & 2 & Não & Não & 3,9630 & 1,0000 \\
\hline
\end{tabular}

Fonte: Autoria própria com auxílio do Pacote Estatístico S-Plus

Os três índices de inflação considerados apresentam estruturas de defasagem similares, com a constante estatisticamente significativa, enquanto a taxa SELIC apresenta também uma tendência determinística significativa na primeira defasagem. O índice BOVESPA apresenta uma estrutura com defasagem mais baixa, sem a presença da constante ou tendência significativa sobre a primeira defasagem.

\section{Apresentação e Análise de Resultados}

É importante destacar que não é objeto deste estudo estabelecer as relações de causalidade entre as variáveis analisadas, mas sim estabelecer um meio que permita gerar cenários possíveis a partir deste conjunto de variáveis. Assim, cada variável é tratada em um sistema de múltiplas equações de séries de tempo como o VAR. Uma vez que não é definida a relação de causa e efeito entre as variáveis consideradas no modelo, assume-se que as variáveis podem interferir simultaneamente sobre o comportamento, ao longo do tempo, de outras variáveis do modelo, e o VAR procura capturar as dinâmicas de longo prazo das séries de tempo.

As séries de tempo consideradas para a elaboração dos cenários são cointegradas se nenhuma destas séries for estacionária, e se existir uma combinação linear que transforma as séries para estacionárias. A verificação de estacionaridade das séries de tempo é apresentada na seção 4.1. A ordem do modelo VAR é determinada a partir de critérios de seleção especificados, onde é escolhida a defasagem ou lags " $p$ " que minimize os valores para $\mathrm{AIC}, \mathrm{BIC}$ e HQC, com $\mathrm{p}_{\text {máx }}=6$. A Tabela 3 apresenta os resultados das estimativas do modelo VAR para os critérios de seleção AIC, BIC e HQC, com valores máximos de defasagem de 6 meses.

Tabela 3 - Critérios de Seleção para a ordem do modelo VAR(p)

\begin{tabular}{cccc}
\hline $\mathbf{P}$ & $\mathrm{AIC}$ & $\mathrm{BIC}$ & $\mathrm{HQC}$ \\
\hline 1 & 3156,11 & 3247,60 & 3193,27 \\
2 & 2904,28 & 3072,02 & 2972,41 \\
3 & 2905,43 & 3149,42 & 3004,53 \\
4 & 2908,50 & 3228,74 & 3038,57 \\
5 & 2920,13 & 3316,61 & 3081,16 \\
6 & 2943,56 & 3416,29 & 3135,56 \\
\hline
\end{tabular}

Fonte: Autoria própria com auxílio do pacote estatístico S-Plus

Uma vez que o valor " $p$ " denotado na tabela anterior, que diz respeito a defasagem igual a 2 foi o menor valor obtido para os 3 critérios de seleção, então o modelo a ser considerado para as projeções é VAR(2) com o critério AIC. A Tabela 4 apresenta os coeficientes para o modelo VAR(2) gerados a partir do critério de AlC, assim como o erro padrão e estatística t para a constante e respectivos coeficientes.

Tabela 4 - Coeficientes do modelo VAR(2) e Diagnóstico da Regressão

\begin{tabular}{|c|c|c|c|c|c|}
\hline $\begin{array}{c}\text { Coeficientes do } \\
\text { Modelo e } \\
\text { estatísticas }\end{array}$ & INPC & IGP-M & IPCA & IBOVESPA & SELIC \\
\hline (Intercept) & 6,7882 & 1,7438 & 5,4733 & 1179,4057 & 0,0117 \\
\hline (t.stat) & 4,1533 & 0,9231 & 4,9064 & 0,5684 & 0,6053 \\
\hline INPC.lag1 & 1,3761 & $-0,3425$ & 0,0305 & $-88,7673$ & 0,0002 \\
\hline
\end{tabular}


Análise de cointegração e geração de cenários na alocação de investimentos em previdência complementar

\begin{tabular}{|c|c|c|c|c|c|}
\hline IGP.M.lag1 & 0,2561 & 1,6885 & 0,1619 & -14.0758 & $-0,0009$ \\
\hline (std.err) & 0,0696 & 0,0804 & 0,0475 & 88,3618 & 0,0008 \\
\hline (t.stat) & 3,6797 & 20,9893 & 3,4078 & $-0,1593$ & $-1,0487$ \\
\hline IPCA.lag1 & 0,0521 & 0,5985 & 1,2741 & 233,1163 & 0,0007 \\
\hline (std.err) & 0,2604 & 0,3010 & 0,1778 & 330,6284 & 0,0031 \\
\hline (t.stat) & 0,2000 & 1,9884 & 7,1677 & 0,7051 & 0,2415 \\
\hline Bovespa.lag1 & 0,0000 & $-0,0002$ & 0,0000 & 0,9750 & 0,0000 \\
\hline (std.err) & 0,0001 & 0,0001 & 0,0000 & 0,0816 & 0,0000 \\
\hline (t.stat) & 0,3567 & $-2,3782$ & 0,6335 & 11,9492 & $-1,1569$ \\
\hline Selic.lag1 & $-8,1654$ & $-17,9708$ & $-3,6419$ & 3362,8492 & 1,5969 \\
\hline (std.err) & 5,6284 & 6,5054 & 3,8416 & 7145,4602 & 0,0663 \\
\hline (t.stat) & $-1,4507$ & $-2,7624$ & $-0,9480$ & 0,4706 & 24,0750 \\
\hline INPC.Iag2 & $-0,4073$ & 0,4212 & $-0,0364$ & 162,3674 & $-0,0004$ \\
\hline (std.err) & 0,1682 & 0,1944 & 0,1148 & 213,5760 & 0,0020 \\
\hline (t.stat) & $-2,4212$ & 2,1664 & $-0,3168$ & 0,7602 & $-0,2060$ \\
\hline IGP.M.lag2 & $-0,2318$ & $-0,7367$ & $-0,1386$ & $-29,9544$ & 0,0010 \\
\hline (std.err) & 0,0680 & 0,0786 & 0,0464 & 86,3827 & 0,0008 \\
\hline (t.stat) & $-3,4068$ & $-9,3673$ & $-2,9840$ & $-0,3468$ & 1,2842 \\
\hline IPCA.lag2 & $-0,0668$ & $-0,6805$ & $-0,3145$ & $-315,8838$ & $-0,0006$ \\
\hline (std.err) & 0,2573 & 0,2974 & 0,1756 & 326,6214 & 0,0030 \\
\hline (t.stat) & $-0,2595$ & $-2,2886$ & $-1,7912$ & $-0,9671$ & $-0,2035$ \\
\hline Bovespa.lag2 & $-0,0001$ & 0,0001 & $-0,0001$ & $-0,0279$ & 0,0000 \\
\hline (std.err) & 0,0001 & 0,0001 & 0,0000 & 0,0879 & 0,0000 \\
\hline (t.stat) & $-1,7788$ & 0,7852 & $-1,8475$ & $-0,3168$ & $-0,3564$ \\
\hline Selic.lag2 & 8,8572 & 18,8809 & 4,0674 & $-2721,7211$ & $-0,5917$ \\
\hline (std.err) & 5,7158 & 6,6064 & 3,9013 & 7256,3626 & 0,0674 \\
\hline (t.stat) & 1,5496 & 2,8580 & 1,0426 & $-0,3751$ & $-8,7848$ \\
\hline
\end{tabular}

Fonte: Autoria própria com auxílio do pacote estatístico S-Plus

Na Tabela 5 são apresentados os resultados obtidos para o teste de cointegração de Johansen entre as variáveis econômicas, já que a ordem do modelo VAR cointegrado é igual a $p-1=1$. Uma vez que o número de vetores de cointegração é dado pelo número de autovalores de $\prod$ diferentes de zero, são apresentadas as estatísticas $\operatorname{LR}_{\text {trace }}(r)$ e $\operatorname{LR}_{\text {max }}(r)$ para o teste de hipóteses da significância dos autovalores.

Tabela 5 - Teste de Cointegração de Johansen

\begin{tabular}{cccccccc}
\hline & Eigenvalue & Trace Stat & $\begin{array}{c}\mathbf{9 9 \%} \\
\text { CV }\end{array}$ & $\begin{array}{c}\mathbf{9 5 \%} \\
\text { CV }\end{array}$ & Max Stat & $\begin{array}{c}\mathbf{9 9 \%} \\
\text { CV }\end{array}$ & $\begin{array}{c}\mathbf{9 5 \%} \\
\text { CV }\end{array}$ \\
\hline$H(0)++^{* *}$ & 0,245 & 90,643 & 77,740 & 85,780 & 45,025 & 36,410 & 41,580 \\
$H(1)$ & 0,128 & 45,618 & 54,640 & 61,240 & 21,844 & 30,330 & 35,680 \\
$H(2)$ & 0,065 & 23,775 & 34,550 & 40,490 & 10,732 & 23,780 & 28,830 \\
$H(3)$ & 0,059 & 13,043 & 18,170 & 23,460 & 9,664 & 16,870 & 21,470 \\
$H(4)$ & 0,021 & 3,379 & 3,740 & 6,400 & 3,379 & 3,740 & 6,400 \\
\hline
\end{tabular}

Fonte: Autoria Própria com Auxílio do Pacote Estatístico S-Plus

Observa-se que os autovalores estimados são $0,245,0,128,0,065,0,059$ e 0,021 apresentados na Tabela 5. O primeiro teste de hipótese consiste em verificar a aceitação ou rejeição da $H_{0}\left(r_{0}=0\right)$ contra $H_{1}\left(r_{0}>0\right)$, valendo-se de um nível de significância de $1 \%$ tanto para a estatística de Traço quanto para a estatística de Máximo Auto-Valor. Com base no resultado gerado existem evidências para rejeitar a hipótese nula $H_{0}\left(r_{0}=0\right)$. Assim, é possível afirmar que existe pelo menos 1 vetor de cointegração que determina a relação de longo prazo entre as 5 variáveis.

O próximo passo do teste de Johansen consiste em verificar o nível de significância do próximo autovalor por meio de teste de hipóteses, ou seja, testar $H_{0}\left(r_{0}=1\right)$ contra $H_{1}\left(r_{0}>1\right)$. Porém, tanto a estatística de Traço quanto a do Máximo Auto-Valor indicam que não existem evidências que levem a rejeitar a hipótese nula; portanto é possível concluir que existe apenas um vetor de cointegração que determina a relação de longo prazo entre as 5 variáveis.

Uma vez que existe cointegração entre as séries temporais, ou seja, que existe relação de longo prazo entre as variáveis, o próximo passo consiste em identificar o mecanismo de correção de erro, para verificar a velocidade de ajustamento dos desequilíbrios de curto prazo em relação ao equilíbrio de longo prazo.

\subsection{Geração de Cenários a partir do Modelo VAR}

Nas seções anteriores foram apresentadas as etapas necessárias para a simulação, baseada em relações de longo prazo, das variáveis econômicas e do mercado financeiro. Os dados utilizados consistem em séries de tempo mensais, que correspondem aos principais componentes de remuneração dos títulos públicos federais, atrelados aos índices de preços e a taxa de juros, que representam uma parcela significativa dos ativos que compõem as carteiras do segmento de renda fixa das EFPC, além da parcela investida no segmento de renda variável, representada pelo índice BOVESPA. 
O resultado gerado pelo processo de simulação consiste em 100 cenários possíveis, que levam em consideração as relações de longo prazo das séries de tempo, compreendendo um período entre os meses de janeiro de 2008 e dezembro de 2047. Cabe lembrar que o período empregado na análise de cointegração compreende entre julho de 1994 e dezembro de 2007, pautando-se na vigência do Real como moeda e efetivo controle inflacionário.

A Figura 1 apresenta a variação média simulada por meio do modelo vetorial autoregressivo com Correção de Erros VECM para o horizonte de 40 anos, com a ajuda do pacote estatístico S-P/us. Também apresenta a taxa equivalente anual para cada série, levando-se em consideração a variação acumulada no período de 40 anos.

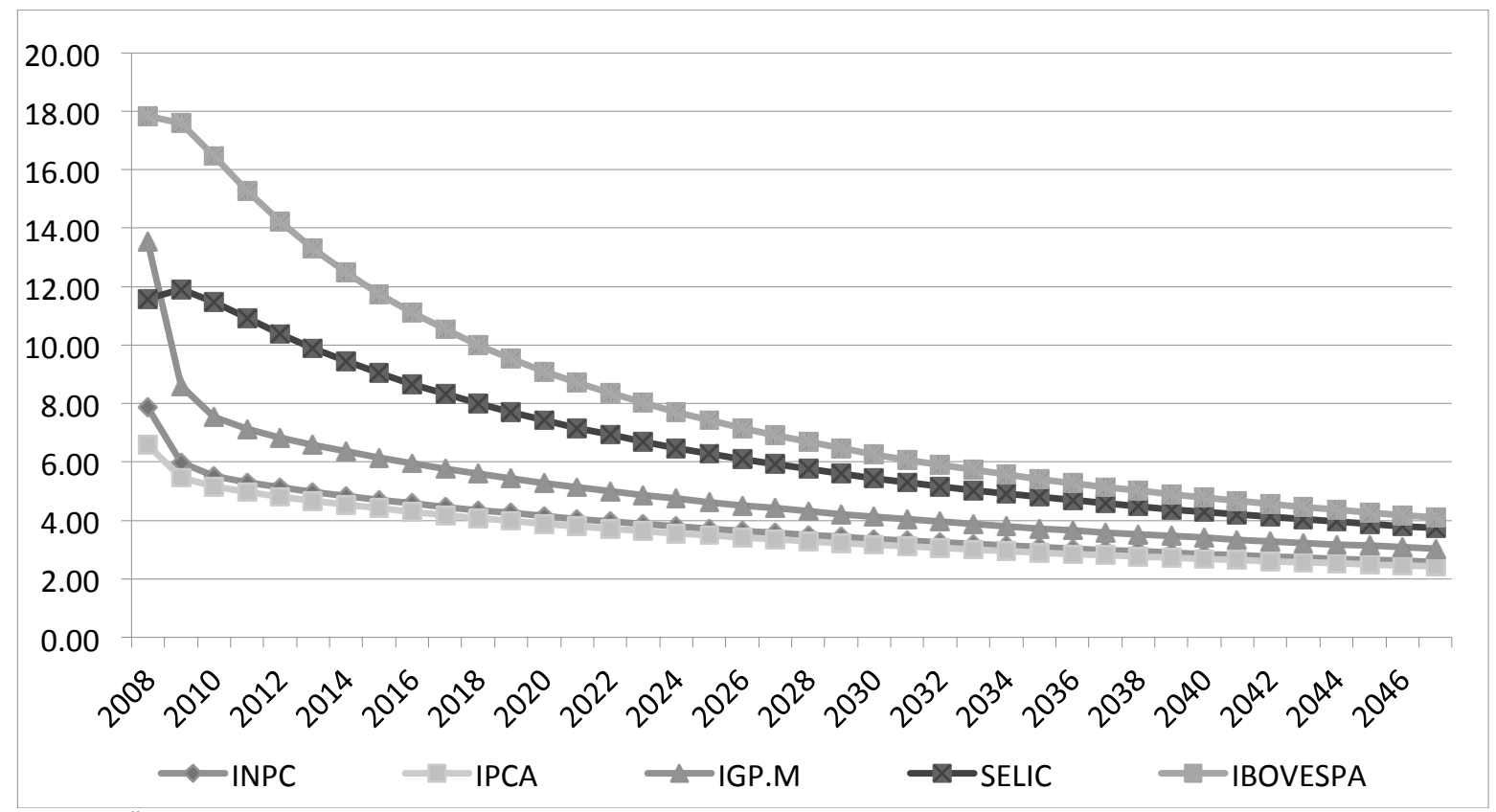

Figura 1 - Variação Anual em Horizonte de 40 anos

Considerando-se inicialmente um período de 5 anos, vê-se que à exceção do ano de 2008, os índices de inflação INPC e IPCA apresentam variações abaixo de $6,00 \%$ ao ano, com tendência de redução gradual ao longo do tempo. A taxa SELIC e o índice BOVESPA apresentam ganhos reais elevados nos primeiros 5 anos, com movimento de redução gradual ao longo do tempo, o que sinaliza um tendência de estabilidade na relação entre as variáveis analisadas.

Ao ampliar o horizonte para 10 anos percebe-se que a inflação permanece sob controle, com taxas inferiores a $4,50 \%$ ao ano, enquanto os ganhos auferidos pelo pela taxa SELIC reduzem substancialmente, apresentando um ganho real médio em relação ao INPC de apenas $3,70 \%$ ao ano, o que para os padrões observados nos últimos anos pode ser considerado baixo.

A tendência de queda no índice IGP-M também é verificada, apesar de apresentar um incremento de aproximadamente $2,10 \%$ ao ano, em média, quando observado o período de 10 anos, reduzindo para $1,09 \%$ ao ano, em média, para o período de 40 anos. Foram definidos 4 cenários construídos a partir das informações geradas pelas projeções do modelo VECM. A composição de cada cenário seguiu os seguintes critérios:

- Cenário 1 (C1): variação anual, acrescida da taxa equivalente anual, calculada a partir da variação estimada em horizonte de 40 anos pelo modelo VECM, partindo-se das variações observadas em 2007;

- Cenário 2 (C2): variação estimada menos o erro padrão da média amostral, ambos estimados pelo modelo VECM;

- Cenário 3 (C3): variação estimada pelo modelo VECM, e

- Cenário 4 (C4): variação estimada adicionado ao erro padrão da média amostral, ambos obtidos pelo modelo VECM.

A composição do Cenário 1 nada mais é que uma espécie de suavização das curvas, uma vez que as taxas de incremento anual para cada uma das séries temporais são obtidas a partir das variações acumuladas em todo o horizonte de 40 anos, tendo como valores iniciais as variações observadas em 2007.

A escolha de definir os Cenários 2, 3 e 4, respectivamente, em função dos valores estimados e seus respectivos erros (à exceção do Cenário 3), se justifica à medida que os valores estimados pelo modelo VECM são médias aritméticas, calculadas a partir de valores simulados, que seguem distribuição de probabilidade Normal multivariada, geradas por meio de simulação de Monte Carlo. 
Uma vez que a incerteza sobre os valores estimados tende a aumentar com o passar do tempo, em função das limitações que envolvem a geração de projeções em séries temporais, a escolha de definir os cenários em torno dos valores estimados (médias) parece bastante razoável, já que a amplitude dos valores pode sugerir situações pouco consistentes, como taxas negativas de juros, ou longos períodos de deflação.

Neste caso, ao invés de construir os cenários com base nos desvios em relação à média, mesmo aqueles que eventualmente poderiam representar cenários pouco prováveis, eles são construídos tendo como base a tendência central que representa a relação de equilíbrio, de longo prazo, das variáveis.

Por exemplo, a variação do INPC no ano de 2008 para o Cenário 1 foi calculada a partir do INPC observado no mês de dezembro/2007, em forma de fator e multiplicado pela taxa equivalente anual, que é $3,81 \%$. Já a variação do INPC no Cenário 2, foi obtida por meio da subtração do erro padrão da média. 0 INPC para o Cenário 3 consiste no valor estimado, enquanto no Cenário 4 o erro padrão é somado à média.

A Figura 2 apresenta a variação nos 4 cenários $C 1, C 2, C 3$ e C4, respectivamente, para as variáveis consideradas no horizonte de 40 anos.

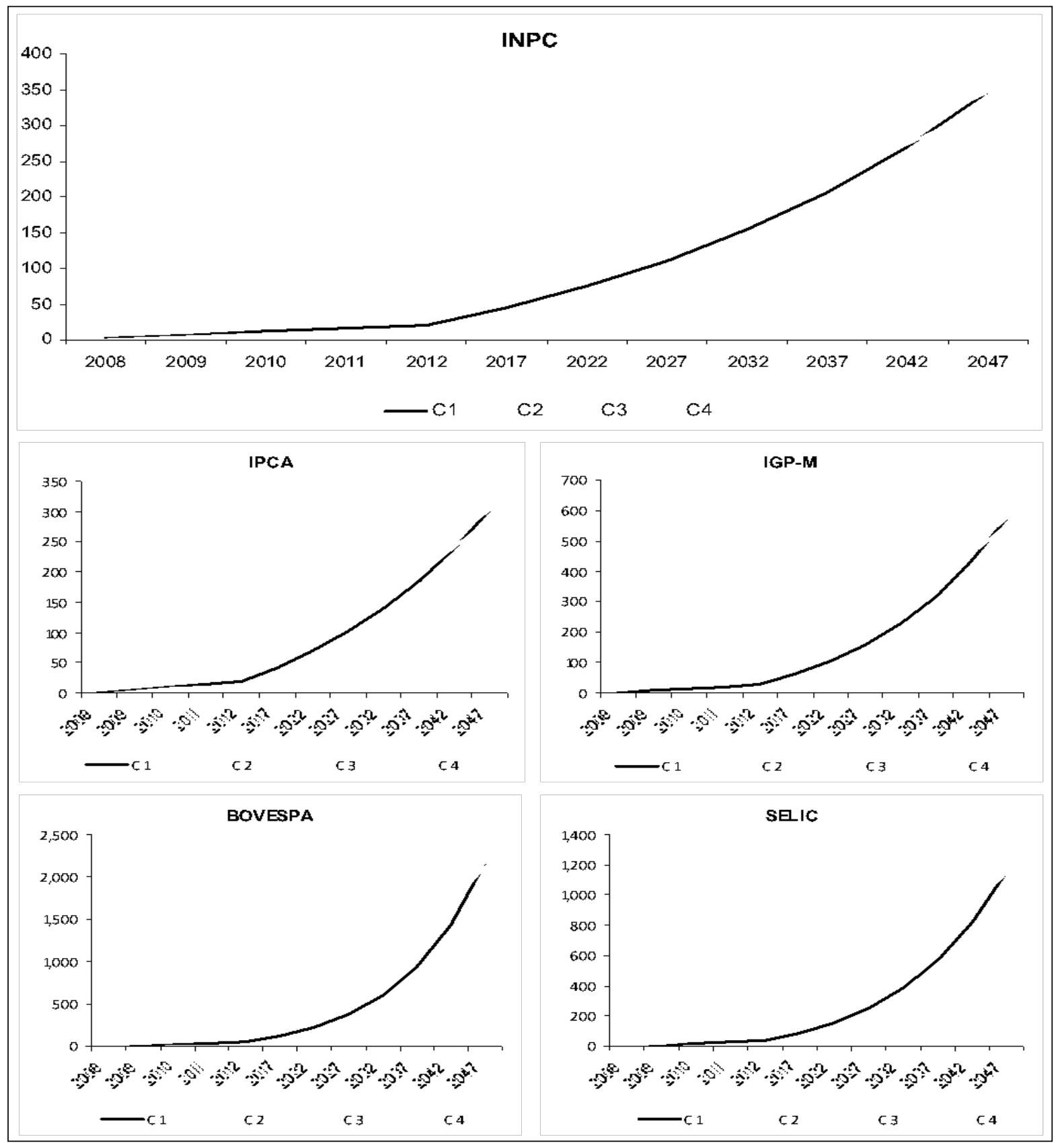

Figura 2 - Variação Acumulada em 4 Cenários para as Variáveis Consideradas na Pesquisa

A Tabela 6 apresenta a variação nos 4 cenários (C1, C2, C3 e C4) para as variáveis consideradas no modelos para um horizonte de 40 anos. 
A redução em todos os índices atrelados aos títulos de renda fixa, a saber: IPCA, IGP-M e taxa SELIC, apresentados em todos os cenários, confirmam tendência de redução sobre os prêmios pagos no segmento de renda fixa. Por outro lado, a expectativa sobre o ganho real no segmento de renda variável, representado pelo índice BOVESPA, permanece elevada. No período de 5 anos a expectativa de ganho real acumulado é de aproximadamente $52,5 \%$, passando a $117,5 \%$ no acumulado em 10 anos. A taxa SELIC apresenta ganhos reais acumulados de $24,7 \%$ e $54,9 \%$, em 5 e 10 anos, respectivamente.

Tabela 6 - Variação Acumulada - Valores Simulados (Média Anual)

\begin{tabular}{|c|c|c|c|c|c|c|}
\hline ANO & CENÁRIO & INPC & IPCA & IGPM & BOVESPA & SELIC \\
\hline \multirow{4}{*}{2008} & CI & 3,81 & 3,55 & 4,88 & 8,11 & 6,54 \\
\hline & $\mathrm{C} 2$ & 5,36 & 4,36 & 9,99 & 9,30 & 10,85 \\
\hline & C3 & 7,87 & 6,58 & 13,55 & 17,83 & 11,59 \\
\hline & $\mathrm{C} 4$ & 10,39 & 8,79 & 17,10 & 26,36 & 12,32 \\
\hline \multirow{4}{*}{2009} & C1 & 7,76 & 7,23 & 10,00 & 16,89 & 13,50 \\
\hline & $\mathrm{C} 2$ & 10,32 & 8,82 & 18,23 & 26,53 & 23,61 \\
\hline & C3 & 14,31 & 12,41 & 23,31 & 38,56 & 24,88 \\
\hline & C4 & 18,30 & 15,99 & 28,40 & 50,59 & 26,15 \\
\hline \multirow{4}{*}{2010} & CI & 11,87 & 11,04 & 15,38 & 26,37 & 20,92 \\
\hline & $\mathrm{C2}$ & 15,63 & 13,67 & 26,47 & 46,71 & 37,49 \\
\hline & C3 & 20,63 & 18,21 & 32,61 & 61,37 & 39,20 \\
\hline & C4 & 25,62 & 22,75 & 38,74 & 76,02 & 40,91 \\
\hline \multirow{4}{*}{2011} & $\mathrm{Cl}$ & 16,13 & 14,99 & 21,01 & 36,62 & 28,83 \\
\hline & $\mathrm{C} 2$ & 21,21 & 18,77 & 35,03 & 69,16 & 52,31 \\
\hline & C3 & 27,02 & 24,08 & 42,05 & 86,02 & 54,39 \\
\hline & C4 & 32,84 & 29,40 & 49,06 & 102,88 & 56,47 \\
\hline \multirow{4}{*}{2012} & C1 & 20,55 & 19,07 & 26,92 & 47,71 & 37,25 \\
\hline & $\mathrm{C} 2$ & 27,01 & 24,07 & 43,96 & 93,66 & 68,03 \\
\hline & C3 & 33,54 & 30,06 & 51,75 & 112,47 & 70,43 \\
\hline & C4 & 40,07 & 36,04 & 59,54 & 131,27 & 72,82 \\
\hline \multirow{4}{*}{2017} & C1 & 45,33 & 41,78 & 61,08 & 118,17 & 88,37 \\
\hline & $\mathrm{C} 2$ & 58,83 & 52,89 & 93,69 & 245,10 & 159,59 \\
\hline & C3 & 68,14 & 61,47 & 104,57 & 271,56 & 163,17 \\
\hline & C4 & 77,45 & 70,06 & 115,45 & 298,03 & 166,74 \\
\hline \multirow{4}{*}{2022} & Cl & 75,19 & 68,83 & 104,44 & 222,25 & 158,54 \\
\hline & C2 & 94,66 & 84,90 & 151,35 & 443,03 & 272,38 \\
\hline & C3 & 106,09 & 95,47 & 164,61 & 475,39 & 276,83 \\
\hline & C4 & 117,52 & 106,04 & 177,88 & 507,75 & 281,29 \\
\hline \multirow{4}{*}{2027} & Cl & 111,20 & 101,03 & 159,48 & 375,98 & 254,84 \\
\hline & $\mathrm{C} 2$ & 134,17 & 119,81 & 216,61 & 686,62 & 406,24 \\
\hline & C3 & 147,39 & 132,04 & 231,89 & 723,96 & 411,43 \\
\hline & C4 & 160,61 & 144,27 & 247,17 & 761,29 & 416,61 \\
\hline \multirow{4}{*}{2032} & C1 & 154,60 & 139,37 & 229,32 & 603,05 & 387,01 \\
\hline & C2 & 177,24 & 157,50 & 289,33 & 975,53 & 561,13 \\
\hline & C3 & 192,03 & 171,19 & 306,39 & $1.017,26$ & 566,95 \\
\hline & C4 & 206,82 & 184,89 & 323,46 & $1.058,98$ & 572,78 \\
\hline \multirow{4}{*}{2037} & Cl & 206,93 & 185,02 & 317,97 & 938,44 & 568,42 \\
\hline & $\mathrm{C} 2$ & 223,82 & 197,90 & 369,45 & $1.309,60$ & 737,01 \\
\hline & C3 & 240,03 & 212,92 & 388,12 & $1.355,29$ & 743,41 \\
\hline & C4 & 256,23 & 227,94 & 406,80 & $1.400,98$ & 749,81 \\
\hline \multirow{4}{*}{2042} & C1 & 270,01 & 239,38 & 430,48 & $1.433,84$ & 817,39 \\
\hline & $\mathrm{C} 2$ & 273,85 & 241,00 & 456,92 & $1.688,72$ & 933,86 \\
\hline & C3 & 291,37 & 257,23 & 477,08 & $1.738,06$ & 940,79 \\
\hline & C4 & 308,88 & 273,46 & 497,25 & $1.787,40$ & 947,72 \\
\hline \multirow{4}{*}{2047} & C1 & 346,05 & 304,11 & 573,27 & $2.165,57$ & $1.159,11$ \\
\hline & $\mathrm{C} 2$ & 327,32 & 286,75 & 551,73 & $2.112,83$ & $1.151,69$ \\
\hline & C3 & 346,05 & 304,11 & 573,27 & $2.165,57$ & $1.159,11$ \\
\hline & C4 & 364,78 & 321,47 & 594,82 & $2.218,31$ & $1.166,53$ \\
\hline
\end{tabular}

Fonte: Autoria própria

A partir do momento em que os diversos cenários foram gerados, é possível obter indícios sobre os prováveis reflexos dos indicadores sobre a carteira de investimentos. As condições gerais para as decisões, e que se refletem diretamente sobre as decisões de uma EFPC, estão especificadas na Política de Investimentos. Neste caso, os limites máximos definidos são de $75 \%$ para o segmento de renda fixa e de $25 \%$ para o segmento de renda variável.

A carteira de renda fixa se divide ainda nos fatores Taxa SELIC, Pré-Fixado e inflação (correção monetária pelos índices IPCA e (GP-M), enquanto o segmento de renda variável é integralmente referenciado pelo índice BOVESPA. É importante destacar que os títulos com correção monetária pela inflação também possuem pagamento de juros anuais de $6,00 \%$.

A avaliação da perfomance da carteira de investimentos leva em consideração 5 táticas de alocações, pautadas nos cenários elaborados, com a participação de cada fator expressa em forma de percentual do total da carteira de investimento. As características das alocações táticas são resumidas na Figura 3. 
As táticas avaliadas prevêem a migração ou balanceamento entre os fatores ao longo do tempo, ou seja, os percentuais definidos para cada segmento e fator permanecem constantes ao longo dos 40 anos, considerando que os resgates e aplicações futuras ocorrerão de maneira a manter a relação definida inicialmente na projeção.

O desempenho dos fatores é apurado por meio do excesso de retorno, que é calculado descontando a variação obtida pelo fator da variação do benchmark. O benchmark consiste na variação do INPC acrescido de juros de $6,00 \%$ ao ano. No caso do IPCA e IGP-M, as variações dos fatores também são acrescidas de $6,00 \%$ ao ano, enquanto a taxa SELIC e o índice BOVESPA consistem somente das variações acumuladas nos períodos em análise.

\begin{tabular}{|c|c|c|}
\hline & Renda Fixa & Renda Variável \\
\hline Tática 1 & $\begin{array}{l}\text { - } \quad \text { Concentração em inflação; } \\
\text { - } \quad \text { Participação entre } 5 \% \text { e 10\% dos } \\
\text { investimentos em taxa SELIC. }\end{array}$ & - $\quad$ Alocação de $25 \%$. \\
\hline Tática 2 & $\begin{array}{ll} & \text { Concentração em taxa SELIC; } \\
\text { - } & \text { Participação limitada em } 20 \% \text { para } \\
\text { inflação. }\end{array}$ & - $\quad$ Alocação de $25 \%$. \\
\hline Tática 3 & $\begin{array}{l}\text { Equilíbrio nos fatores com diferença } \\
\text { máxima de } 5 \% \text { entre eles. }\end{array}$ & - $\quad$ Alocação de $25 \%$. \\
\hline Tática 4 & $\begin{array}{ll} & \text { Concentração em IPCA; } \\
\text { - } \quad \text { Participação entre 5\% e 10\% dos } \\
\text { investimentos em taxa SELIC. }\end{array}$ & - $\quad$ Alocação de $20 \%$. \\
\hline Tática 5 & $\begin{array}{ll} & \text { Concentração em IGP-M; } \\
\text { - } \quad \text { Participação entre } 5 \% \text { e } 10 \% \text { dos } \\
\text { investimentos em taxa SELIC. }\end{array}$ & - $\quad$ Alocação de $25 \%$. \\
\hline
\end{tabular}

Figura 3 - Características das 5 Táticas por Segmento de Aplicação

A escolha do excesso de retorno como medida de desempenho, ao invés de outros índices conhecidos, como Sharpe ou Sortino, é justificada em função do estudo envolver a avaliação de resultados em cenários probabilísticos, enquanto tais índices são mais aplicados em situações onde a avaliação de desempenho leva em consideração o desempenho passado dos ativos. Além disso, o excesso de retorno fornece uma informação complementar relevante no aspecto atuarial do plano de benefícios, que é o superávit ou déficit em relação ao benchmark.

A alocação Tática 1 prevê maior participação em ativos atrelados ao IPCA e IGP-M, mantendo-se apenas $5 \%$ da carteira de investimentos em ativos atrelados à Taxa SELIC, para fazer frente às obrigações como, por exemplo, o pagamento de benefícios, enquanto a participação no segmento de renda variável é mantida no limite máximo previsto na Política de Investimentos.

Esta tática apresenta pior resultado no Cenário 1 (mais conservador), apresentando um desempenho abaixo do benchmark já nas primeiras janelas de avaliação deste cenário. Nos demais cenários (C2, C3 e C4, respectivamente) o desempenho da carteira de investimentos apresenta excesso de retorno na janela de 30 anos, sem, entretanto manter o desempenho acima do INPC, acrescido de 6,00\%, nos horizontes mais longos. Os resultados são apresentados na Tabela 7.

Tabela 7 - Tática 1: Alocação e desempenho

\begin{tabular}{ccccccccc}
\hline $\begin{array}{l}\text { Período } \\
\text { (janela) }\end{array}$ & \multicolumn{3}{c}{ Participação (\%) Carteira } & \multicolumn{4}{c}{ Excesso de Retorno } \\
\hline $2008-2012$ & Ipca & Igpm & Selic & lbovespa & C1 & C2 & C3 & C4 \\
$2008-2017$ & 35 & 35 & 5 & 25 & $-2,32$ & 12,39 & 14,92 & 17,45 \\
$2008-2022$ & 35 & 35 & 5 & 25 & $-6,46$ & 32,04 & 34,36 & 36,69 \\
$2008-2027$ & 35 & 35 & 5 & 25 & $-13,28$ & 53,78 & 54,69 & 55,60 \\
$2008-2032$ & 35 & 35 & 5 & 25 & $-23,70$ & 73,07 & 71,16 & 69,25 \\
$2008-2037$ & 35 & 35 & 5 & 25 & $-38,36$ & 83,67 & 77,13 & 70,59 \\
$2008-2042$ & 35 & 35 & 5 & 25 & $-56,66$ & 76,96 & 63,34 & 49,72 \\
$2008-2047$ & 35 & 35 & 5 & 25 & $-74,56$ & 40,95 & 16,91 & $-7,13$ \\
\hline
\end{tabular}

Fonte: Autoria Própria

A alocação referente à Tática 2 prevê a concentração dos recursos da carteira de investimentos em ativos atrelados a taxa SELIC, e restringe a participação em ativos atrelados ao INPC e IGP-M em 20\%, enquanto o percentual de recursos no índice Bovespa corresponde a 25\%.

Nesta tática, com os resultados apresentados na Tabela 8 , o excesso de retorno é verificado em 3 cenários e apenas nos primeiros 5 anos, ficando abaixo do benchmark nas demais janelas em todos os cenários. A escolha desse tipo de tática pode ser representada, por exemplo, pela escolha de buscar apenas ativos financeiros, cujo estilo de gestão busca reproduzir os retornos de curto prazo, atrelados com a taxa SELIC.

Em muitos casos os gestores de fundos de investimentos, mesmo aqueles direcionados para clientes como os fundos de pensão, acabam por reproduzir o estilo de gestão referenciado pela taxa de juros SELIC. 
Neste caso, a tática pode satisfazer a necessidade inicial da EFPC, de rentabilidade nos 5 primeiros anos, porém insuficiente para períodos mais longos.

A Tabela 9 apresenta os resultados para a Tática 3, tendo igual participação entre todos os fatores, com $25 \%$ dos recursos disponíveis alocados em cada um deles. A proposta desta tática é de que as variações negativas, em um determinado fator, sejam compensadas por variações positivas em outros fatores, de maneira a minimizar eventuais perdas de rentabilidade ao longo do tempo.

Tabela 8 - Tática 2: Alocação e Desempenho

\begin{tabular}{ccccccccc}
\hline $\begin{array}{c}\text { Período } \\
\text { (janela) }\end{array}$ & \multicolumn{2}{c}{ Participação (\%) Carteira } & \multicolumn{4}{c}{ Excesso de Retorno } \\
& Ipca & Igpm & $\begin{array}{c}\text { Seli } \\
\text { I }\end{array}$ & $\begin{array}{c}\text { Ibovesp } \\
\text { If }\end{array}$ & C1 & C2 & C3 & C4 \\
\hline $2008-2012$ & 15 & 5 & 55 & 25 & $-16,52$ & 5,40 & 4,40 & 3,40 \\
$2008-2017$ & 15 & 5 & 55 & 25 & $-49,60$ & 3,01 & $-1,80$ & $-6,60$ \\
$2008-2022$ & 15 & 5 & 55 & 25 & $-111,92$ & $-29,36$ & $-40,83$ & $-52,30$ \\
$2008-2027$ & 15 & 5 & 55 & 25 & $-224,87$ & $-119,42$ & $-141,29$ & $-163,16$ \\
$2008-2032$ & 15 & 5 & 55 & 25 & $-424,34$ & $-308,07$ & $-345,43$ & $-382,79$ \\
$2008-2037$ & 15 & 5 & 55 & 25 & $-770,03$ & $-655,62$ & $-715,47$ & $-775,32$ \\
$2008-2042$ & 15 & 5 & 55 & 25 & $-1.360,76$ & $-1.250,48$ & $-1.342,49$ & $-1.434,50$ \\
$2008-2047$ & 15 & 5 & 55 & 25 & $-2.359,33$ & $-2.221,82$ & $-2.359,33$ & $-2.496,84$ \\
\hline
\end{tabular}

Fonte: Autoria Própria

Porém, em 3 cenários ( $C 2, C 3$ e C4, respectivamente) há excesso de rentabilidade somente nas janelas até 20 anos, quando o desempenho da carteira de investimentos já não consegue superar o desempenho do benchmark, a não ser que ocorra uma situação atípica como, por exemplo, uma valorização excessiva sobre o índice Bovespa e que eleve a rentabilidade da carteira de investimentos. Neste caso, apesar de possível, tendo em vista o histórico de valorização do índice Bovespa, não há elementos que venham a garantir valorizações substanciais no futuro.

Tabela 9 - Tática 3: Alocação e desempenho

\begin{tabular}{ccccccccc}
\hline $\begin{array}{l}\text { Período } \\
\text { (janela) }\end{array}$ & \multicolumn{3}{c}{ Participação (\%) Carteira } & \multicolumn{4}{c}{ Excesso de Retorno } \\
& Ipca & lgpm & Selic & lbovespa & C1 & C2 & C3 & C4 \\
\hline $2008-2012$ & 25 & 25 & 25 & 25 & $-7,79$ & 10,12 & 11,29 & 12,46 \\
$2008-2017$ & 25 & 25 & 25 & 25 & $-23,03$ & 21,89 & 21,44 & 21,00 \\
$2008-2022$ & 25 & 25 & 25 & 25 & $-51,03$ & 23,71 & 19,80 & 15,88 \\
$2008-2027$ & 25 & 25 & 25 & 25 & $-100,42$ & 2,28 & $-7,41$ & $-17,11$ \\
$2008-2032$ & 25 & 25 & 25 & 25 & $-185,03$ & $-61,71$ & $-80,29$ & $-98,87$ \\
$2008-2037$ & 25 & 25 & 25 & 25 & $-326,73$ & $-196,37$ & $-228,06$ & $-259,75$ \\
$2008-2042$ & 25 & 25 & 25 & 25 & $-559,66$ & $-442,43$ & $-493,05$ & $-543,67$ \\
$2008-2047$ & 25 & 25 & 25 & 25 & $-936,39$ & $-858,82$ & $-936,39$ & $-1.013,95$ \\
\hline
\end{tabular}

Fonte: Autoria Própria.

A Tabela 10 apresenta os resultados para a Tática 4, tendo maior participação em IPCA com 45\%, enquanto a participação em IGP-M situa-se em 30\%, restando apenas $5 \%$ da carteira de investimentos em ativos atrelados à taxa SELIC, para fazer frente às obrigações como, por exemplo, o pagamento de benefícios. A participação no segmento de renda variável é ligeiramente menor do que nas táticas anteriores, tendo sido destinado $20 \%$ dos recursos disponíveis para investimentos.

Esta tática tem como objetivo buscar maior aderência com o desempenho dos índices de inflação, mantendo-se atrelada com a taxa de juros de curto prazo somente uma parcela menor dos recursos disponíveis para uso imediato. A participação no segmento referenciado pelo índice BOVESPA também é reduzida, uma vez que é o fator que apresenta maior volatilidade, o que pode comprometer o desempenho da carteira.

Observa-se que a Tática 4 apresenta boa aderência com o benchmark, apresentando excesso de ganho em 3 cenários (C2, C3 e C4, respectivamente) na janela de 30 anos, ficando abaixo nas duas janelas mais longas (35 e 40 anos).

Tabela 10 - Tática 4: Alocação e Desempenho

\begin{tabular}{|c|c|c|c|c|c|c|c|c|}
\hline \multirow{2}{*}{$\begin{array}{l}\text { Período } \\
\text { (janela) }\end{array}$} & \multicolumn{4}{|c|}{ Participação (\%) Carteira } & \multicolumn{4}{|c|}{ Excesso de Retorno } \\
\hline & Ipca & Igpm & Selic & $\begin{array}{c}\text { Ibovesp } \\
a\end{array}$ & $\mathrm{Cl}$ & $\mathrm{C} 2$ & C3 & $\mathrm{C} 4$ \\
\hline $2008-2012$ & 45 & 30 & 5 & 20 & $-2,26$ & 9,67 & 11,55 & 13,42 \\
\hline $2008-2017$ & 45 & 30 & 5 & 20 & $-6,40$ & 24,82 & 26,38 & 27,95 \\
\hline $2008-2022$ & 45 & 30 & 5 & 20 & $-13,43$ & 40,83 & 41,06 & 41,29 \\
\hline $2008-2027$ & 45 & 30 & 5 & 20 & $-24,63$ & 53,47 & 51,16 & 48,86 \\
\hline $2008-2032$ & 45 & 30 & 5 & 20 & $-41,45$ & 56,86 & 50,45 & 44,03 \\
\hline $2008-2037$ & 45 & 30 & 5 & 20 & $-64,91$ & 42,77 & 30,12 & 17,48 \\
\hline $2008-2042$ & 45 & 30 & 5 & 20 & $-94,26$ & $-0,42$ & $-22,20$ & $-43,98$ \\
\hline $2008-2047$ & 45 & 30 & 5 & 20 & $-123,91$ & $-89,02$ & $-123,91$ & $-158,80$ \\
\hline
\end{tabular}

Fonte: Autoria Própria 
A Tabela 11 apresenta os resultados para a Tática 5, na qual a maior participação é em IGP-M com 40\%, enquanto a participação em IPCA fica em 30\%, restando apenas $5 \%$ da carteira de investimentos em ativos atrelados a taxa SELIC. A participação no segmento de renda variável é de $25 \%$ dos recursos disponíveis para investimentos.

A Tática 5 tem como objetivo buscar maior aderência com o desempenho dos índices de inflação, mantendo-se atrelada com a taxa de juros de curto prazo somente uma parcela menor dos recursos disponíveis para uso imediato. A participação do segmento referenciado pelo índice BOVESPA é $25 \%$ do total de recursos disponíveis.

Tabela 11 - Tática 5: Alocação e desempenho

\begin{tabular}{|c|c|c|c|c|c|c|c|c|}
\hline \multirow{2}{*}{$\begin{array}{l}\text { Período } \\
\text { (janela) }\end{array}$} & \multicolumn{4}{|c|}{ Participação (\%) Carteira } & \multicolumn{4}{|c|}{ Excesso de Retorno } \\
\hline & Ipca & Igpm & Selic & $\begin{array}{c}\text { Ibovesp } \\
a\end{array}$ & $\mathrm{Cl}$ & $\mathrm{C} 2$ & C3 & C4 \\
\hline $2008-2012$ & 30 & 40 & 5 & 25 & $-1,79$ & 13,72 & 16,37 & 19,03 \\
\hline $2008-2017$ & 30 & 40 & 5 & 25 & $-4,73$ & 35,69 & 38,22 & 40,75 \\
\hline $2008-2022$ & 30 & 40 & 5 & 25 & $-9,01$ & 61,75 & 62,98 & 64,21 \\
\hline $2008-2027$ & 30 & 40 & 5 & 25 & $-14,33$ & 88,59 & 87,17 & 85,75 \\
\hline $2008-2032$ & 30 & 40 & 5 & 25 & $-19,06$ & 111,96 & 106,14 & 100,32 \\
\hline $2008-2037$ & 30 & 40 & 5 & 25 & $-18,48$ & 126,22 & 113,65 & 101,08 \\
\hline $2008-2042$ & 30 & 40 & 5 & 25 & $-1,12$ & 123,93 & 101,40 & 78,88 \\
\hline $2008-2047$ & 30 & 40 & 5 & 25 & 58,39 & 95,27 & 58,39 & 21,51 \\
\hline
\end{tabular}

Fonte: Autoria Própria

A Tática 5 apresenta desempenho superior ao benchmark na maioria dos cenários e janelas, à exceção do Cenário 1, no qual a carteira apresenta desempenho um pouco abaixo do benchmark, porém, recuperando a rentabilidade nos períodos mais distantes.

O comparativo do desempenho das táticas, apresentadas em diversos cenários probabilísticos, revela que a escolha da alocação dos recursos não é um processo trivial. Uma vez que o fluxo dos investimentos e obrigações de uma EFPC se estende por décadas, a gestão dos investimentos não deve buscar simplesmente maximizar o retorno dos investimentos de maneira imediata, mas sim reproduzir o desempenho de um determinado benchmark de longo prazo, de maneira a garantir o cumprimento das obrigações de pagamento de benefícios de aposentadoria e pensão.

De outra maneira, a alocação dos investimentos privilegiaria os ativos que apresentassem melhor desempenho ou potencial de valorização em um determinado período relativamente mais curto, mudando o perfil dos investimentos conforme o rumo do mercado financeiro. Entretanto, a escolha deste estilo de gestão pode causar uma situação na qual as condições do mercado financeiro venham a permanecer desfavoráveis por um determinado período relativamente mais longo, imprimindo perdas ao patrimônio da EFPC em função da tática de investimento escolhida.

Assim, a escolha por parte da EFPC em determinar a melhor tática quanto ao perfil de correção monetária é fundamental, especialmente por se tratar de um momento de consolidação de tendência de redução gradativa dos retornos, anteriormente decorrentes das altas taxas de juros e inflação. A decisão passa a ser crítica em função da possibilidade de uma opção equivocada por parte da EFPC, uma vez que as condições futuras podem não representar as mesmas condições atuais.

\section{Considerações Finais}

A proposta de um estudo de alocação de investimentos sob o prisma de uma EFPC, empregando ferramentas como análise de cointegração e o processo de simulação, buscou desenvolver condições para elaborar cenários probabilísticos que pudessem representar as relações de longo prazo de alguns fatores determinantes para o bom desempenho da carteira de investimentos.

A abordagem da alocação de investimentos em uma EFPC é colocada sob uma perspectiva estratégica, uma vez que tem relação direta com o objetivo principal da própria entidade. Mesmo como um agente importante do mercado financeiro, os fundos de pensão têm características e propostas distintas quanto à gestão dos investimentos, tendo seus objetivos de retorno definidos em longo prazo. Entretanto, a EFPC está inserida em um mercado fundamentado na gestão dos investimentos que busca maximizar o retorno em curto prazo.

Em relação ao primeiro objetivo específico de caracterização do processo decisório envolvendo os investimentos, mais especificamente quanto à aquisição de ativos financeiros foram estabelecidas nas diretrizes de investimento, e trouxeram consigo características em uma EFPC, uma vez que envolve diversos agentes interessados diretamente, como participantes, gestores de investimentos, órgãos de regulamentação, o governo federal ou empresas que recebem investimentos, somente citando aquelas mais importantes. Ou seja, o processo decisório deve se legitimado, especialmente perante os participantes e a organização do plano de previdência em função do compromisso da EFPC em relação à gestão dos investimentos. 
Assim, o estudo se desenvolveu com o propósito de estabelecer um modelo específico de alocação de ativos de investimentos em uma EFPC, que contribuísse para a formulação de uma estratégia de investimentos em longo prazo. Para tanto, a modelagem das relações de longo prazo com um uso de modelos econométricos, mais especificamente aqueles para análise de séries temporais, foi essencial para este propósito.

Quanto ao segundo objetivo específico percebeu-se que a partir da modelagem das relações causais de longo prazo entre os ativos financeiros e indicadores econômicos foi feita por meio de cointegração. Esta métrica consistiu em um conjunto de técnicas estatísticas que permitiram estabelecer um modelo de relações de longo prazo para as séries temporais.

Uma vez que o fluxo das obrigações futuras possui correção pelo índice de inflação INPC acrescido de juro anual de $6 \%$, a análise de cointegração foi aplicada sobre cinco variáveis, que compreendem aos indicadores econômicos e do mercado financeiro: taxa SELIC, e índice BOVESPA, IPCA, INPC e IGP-M. Os dados utilizados no estudo compreendem o período de julho de 1994 a dezembro de 2007. Apesar de estarem disponíveis os dados de períodos anteriores optou-se pela restrição aos períodos mencionados anteriormente, em função dos altos níveis de inflação que caracterizaram a década de 80 e parte da década de 90 . Além disso, o mercado financeiro ainda apresentava poucos instrumentos que permitem as EFPC's de investir em ativos com prazos de vencimentos mais longos. A análise das séries temporais e a análise de cointegração foi realizada por meio do pacote estatístico S-Plus ${ }^{\circledR}$ com o pacote de modelagem de dados financeiros $S+$ FinMetrics ${ }^{\circledR}$.

O terceiro e último objetivo específico consistiu na avaliação de performance da carteira de investimentos pautando-se na formulação dos cenários probabilísticos. O estudo foi desenvolvido segundo uma proposta de modelo de $A L M$, que consiste em uma modelagem financeira que busca relacionar os eventos futuros (pagamento de benefícios de aposentadorias e pensões) com o fluxo de caixa gerado pelas contribuições e investimentos financeiros.

Entretanto, o trabalho ficou restrito à modelagem dos investimentos, mais especificamente a parte relacionada à alocação macro por fatores, separados em dois segmentos: renda fixa e renda variável. No primeiro segmento, composto por ativos com correção monetária por índices de inflação como IPCA e o IGP-M, além dos ativos atrelados a taxa de juros SELIC. O outro segmento, o de renda variável, é composto por ativos referenciados integralmente ao índice Bovespa.

A avaliação da performance dos investimentos foi apurada por meio do excesso de retorno da carteira de investimentos em relação ao benchmark, tendo a participação em cada um dos fatores expressa em percentual do total de recursos disponíveis, para cada um dos cenários. Para tanto, foram definidos 4 cenários definidos a partir da projeção elaborada pelo modelo VECM.

As projeções anuais geradas pelo modelo VECM nada mais são do que médias aritméticas calculadas a partir de valores simulados que seguem distribuição Normal multivariada, geradas por meio de simulação de Monte Carlo. A definição dos cenários se deu em função dos valores estimados, e seus respectivos erros em relação à média.

Uma das restrições encontradas no decorrer do estudo foi a indisponibilidade de séries históricas que pudessem ser utilizadas na análise. E, uma vez que o estudo envolve as relações de longo prazo das variáveis, a modelagem requer um número razoável de observações anuais ou mensais. Desta forma, a solução encontrada foi utilizar os da taxa SELIC e índice BOVESPA observadas em cada mês, criando variáveis que representem o comportamento dos títulos públicos atrelados aos índices de inflação com pagamento de juros anuais de $6 \%$ ao ano. Naturalmente, as variações observadas no mercado secundário de títulos públicos não são consideradas, uma vez que a disposição da EFPC é permanecer com os ativos até o seu vencimento.

\section{Referências}

Almeida, M. I. R. (1997) Por que não desenvolver uma analise ambiental para o planejamento estratégico que tenha lógica, e não seja apenas um agrupamento de informações. In: Conselho Monetário Nacional [ CMN]. Resolução № 3.792/2009. Anais Encontro Nacional da Associação Nacional de Pós-Graduação e Pesquisa em Administração, Rio de Janeiro, RJ, Brazil, 21.

Banco Central do Brasil [ BACEN]. (2007) Brasília: Disponível em https://www3.bcb.gov.br/sgspub/localizarseries/localizarSeries.do?method=prepararTelaLocalizarseries. Recuperado em 16 de Abril de 2007.

Brady, M. (2000) Simulation as an aid in strategy making. Operational Research Society Annual Conference, Dublin, Ireland.

Instituto Brasileiro de Geografia e Estatística [ IBGE]. (2007) Sistema Nacional de Preços ao Consumidor - SNIPC. Rio de Janeiro: Disponível em:

<http://www.ibge.gov.br/home/estatistica/indicadores/precos/inpc_ipca/defaultinpc.shtm>. Recuperado em 15 de abril de 2007.

Enders, W. (2005) Applied econometrics time series. 2a. ed., John Wiley \& Sons, 2005.

Enriquez, E. (1997) O indivíduo preso na armadilha da estrutura estratégica. ERA, 37 (1), 18-29. 
Fleisher, C. S. \& Bensoussan, B. E. (2002) Strategic and competitive analysis: methods and techniques for analyzing business competition. New Jersey: Prentice Hall.

Fundação Getúlio Vargas. (2007) Índices gerais de preços. Disponível em:

<http://www2.fgv.br/dgd/asp/dsp_IGP.asp>. Recuperado em 15 de abril de 2007.

Georganzas, N. C. \& Acar, W. (1995) Scenario-driven planning: learning to manage strategic uncertainty. Westport, Connecticut London: Quorum Books.

Hamilton, J. D. (1994) Time series analysis. New Jersey, Princeton University Press.

Harris, R. I. D. (1995) Using cointegration analysis in economic modelling. Harlow, England: Prentice Hall.

Hendry, D. F. (1995) Dynamic econometrics. Oxford: Oxford University Press.

Jennings, D. (2002) Strategic management: an evaluation of the use of three learning methods. The Journal of Management Development, 655-665. Nottingham, United Kingdom.

Johansen, S. (1988) Statistical analysis of cointegration vectors. Journal of Economic Dynamics and Control, 231254.

Jung, C. F. (2004) Metodologia para pesquisa \& desenvolvimento, aplicada a novas tecnologias, produtos e processos. Rio de Janeiro: Axcel Books do Brasil.

Lûtkepohl, H. (2005). New introduction to multiple time series analysis. Berlim: Springer Verlag.

Margarido, M. A., Oliveira R. S., \& Souza, W. A. (2006) Mercados Futuros e Hedging no Mercado da Soja: O Caso Barreiras. Revista Desenbahia, 5(9).

Mintzberg, H. (2000) Ascensão e queda do planejamento estratégico. São Paulo: Bookman.

Quinn, J. B. (1978) Strategic change: logical incrementalism. Sloan Management Review, 20 (1), 7.

Sargan, J. D. (1964) Wages and prices in the united kingdom: a study in econometric methodology. In P. E. Hart, G. Mills, and J. N. Whittaker. Econometric Analysis for National Economic Planning. London: Butterworths.

Schwartz, R. G. \& Teach, R. D. (2000) Methodology to study firms' strategies and performance over time. Journal of Marketing Theory and Practice, 8 (3).

Simon, H. A. (1997) Models of bounded rationality: empirically grounded economic reason. MIT Press, 3.

Shimizu, T. (1975) Simulação em computador digital. São Paulo: Editora Edgard Blücher.

Utterback, J. M. (1979) Environmental analysis and forecasting in strategic management. EUA: Little, Brown and Company. 